\title{
PENGARUH PENAMBAHAN PEKTIN KULIT JERUK DAN SUKROSA TERHADAP KARAKTERISTIK FISIKOKIMIA DAN ORGANOLEPTIK SELAI JAHE (Zingiber Officinale)
}

\author{
Effect of Addition Of Orange Peel Pectin and Sucrose on Physicochemical Characteristics \\ and Organoleptic of Ginger Jam (Zingiber officinale).
}

\author{
Ana Ummu Mas'ula* dan Hapsari Titi Palupi \\ Prodi Ilmu dan Teknologi Pangan, Fakultas Pertanian, Universitas Yudharta Pasuruan \\ *Penulis korespondensi, email : anaummumasula@yahoo.co.id
}

\begin{abstract}
Jam is a thick textured food product made by cooking crushed fruit mixed with sucrose. The main raw materials used for making jam is empirical ginger. The purpose of this study was todetermine the effect of orange peel pectin and sucrose seen from the physical and chemical quality and acceptability of consumers. The experimental design study is a randomized block design $(R A K)$, had 2 treatments, orange peel pectin concentrations $(0.5 \%, 1 \%)$ and sucrose $(40 \%, 50 \%, 60 \%)$ was repeated 3 times. Parameters measured were jam moisture content, $\mathrm{pH}$, reducing sugar, color and organoleptic (taste, color, texture / consistency and aroma). Data obtained statistical analysis ANOVA using Minitab software and Tukey followed different test, while the organoleptic parameters of statistical analysis using Fridmen test. Results from the study indicate the best treatment contained in the sample of P2S2 (orange peel pectin $1 \%$ and $50 \%$ sucrose) with physicochemical conditions of water content of $32.86 \%, \mathrm{pH}$ of 6.59, 3.08\% reduced sugar, colors L 38.20, and 4,90 organoleptic taste, color 4.90, 4.90 texture, and aroma 4.85.
\end{abstract}

Keywords: ginger jam, orange peel pectin, sucrose

\begin{abstract}
ABSTRAK
Selai merupakan produk makanan bertekstur kental yang dibuat dengan memasak hancuran buah yang dicampur sukrosa. Bahan baku utama yang digunakan untuk pembuatan selai adalah jahe emprit. Tujuan dari penelitian ini adalah untuk mengetahui pengaruh penambahan pektin kulit jeruk dan sukrosa dilihat dari mutu fisik dan kimianya dan daya terima konsumen. Rancangan percobaan penelitian adalah Rancangan Acak Kelompok (RAK), memiliki 2 perlakuan yaitu konsentrasi pektin kulit jeruk $(0,5 \%, 1 \%)$ dan konsentrasi sukrosa $(40 \%, 50 \%$, $60 \%$ ) diulang 3 kali. Parameter selai yang diamati adalah kadar air, $\mathrm{pH}$, gula reduksi, warna dan organoleptik (rasa, warna, tekstur/kekentalan dan aroma). Data yang diperoleh dilakukan analisis statistik anova menggunakan software Minitab 17 dan apabila terjadi pengaruh nyata dilakukan uji beda Tukey, sedangkan parameter organoleptik dilakukan analisis statistik menggunakan uji Fridmen. Hasil dari penelitian menunjukkan perlakuan terbaik terdapat pada sempel P2S2 (pektin kulit jeruk 1\% dan sukrosa 50\%) dengan ketentuan fisikokimia kadar air $32,86 \%$, pH 6,59, gula reduksi 3,08\%, warna L 38,20, serta organoleptik rasa 4,90, warna 4,90, tekstur 4,90, dan aroma 4,85.
\end{abstract}

Kata Kunci : selai jahe, pektin kulit jeruk, sukrosa

\section{PENDAHULUAN}

Tanaman jahe merupakan salah satu tanaman rempah-rempah yang tumbuh baik dan tersebar luas di wilayah Indonesia. Jahe emprit (Zingiber officinale) termasuk komoditas yang diperdagangkan secara luas di dunia. Masyarakat Indonesia umumnya telah mengenal dan memanfaatkan jahe untuk berbagai kepentingan, misalnya sebagai campuran bahan makanan dan minuman mulai dari tingkat tradisional 
sampai tingkat modern. Adanya peningkatan kebutuhan masyarakat terhadap jahe sehingga diperlukan pengolahan jahe emprit menjadi produk olahan yang memiliki nilai ekonomis tinggi.

Selai merupakan salah satu diversifikasi produk olahan jahe. Menurut Fachrudin (1997), selai merupakan produk olahan yang berasal dari sari buah atau buah-buahan yang sudah dihancurkan, kemudian ditambah sukrosa dan dimasak sampai mengental. Selai termasuk makanan semi padat yang terbuat dari campuran $45 \%$ bagian buah dan $55 \%$ bagian sukrosa dengan total padatan terlarut sekitar $65 \%$. Pada pembuatan selai perlu diperhatikan keseimbangan proporsi pektin, asam, dan sukrosa agar terbentuk selai dengan konsistensi seperti gel.

Menurut Yulistiani et al. (2011), dalam proses pembuatan selai diperlukan penambahan pektin dan sukrosa dalam jumlah yang tepat. Penambahan pektin dan sukrosa yang tidak tepat dalam proses pembuatan selai menyebabkan terjadinya pengkristalan dan kekakuan gel. Pembentukan gel yang encer karena kadar sukrosa terlalu tinggi daripada dengan kadar pektin. Menurut Ramadhan (2011), selai yang baik harus memiliki aroma dan rasa buah asli, serta memiliki daya oles yang baik.

Pada proses pembentukan gel, perlu diperhatikan formulasi pektin dan sukrosa pada berbagai jenis buah. Sampai saat ini belum diketahui penambahan pektin dan sukrosa yang tepat pada pembuatan selai jahe. Oleh karena itu, penelitian ini dilakukan dengan tujuan untuk mengetahui pengaruh penambahan pektin dan sukrosa terhadap sifat fisikokimia dan organoleptik selai jahe sesuai SNI 01-37461995 yang memiliki aroma normal, rasa normal, warna normal, kadar air maksimal 35\%, total padatan terlarut $65 \%$, dan $\mathrm{pH} 3,2-3,5$.

\section{METODE PENELITIAN}

\section{Waktu dan Lokasi Penelitian}

Waktu penelitian direncanakan pada bulan April sampai Juli 2018. Tempat penelitian di Laboratorium Pangan Universitas Yudharta Pasuruan dan Laboratorium Biokimia Universitas Brawijaya Malang.

\section{Alat dan Bahan.}

Alat yang digunakan dalam pembuatan selai jahe adalah timbangan, sendok, pisau, baskom, telenan, piring, blender, saringan, wajan, pengaduk, dan homogenizer. Alat-alat lain yang digunakan adalah alat-alat untuk melakukan analisis kimia. Bahan baku utama yang digunakan dalam pembuatan selai jahe adalah jahe emprit yang diperoleh dari pasar tradisional. Bahan penunjang yang digunakan adalah asam sitrat, pektin kulit jeruk, gula pasir (sukrosa), dan air. Selain itu juga digunakan bahan kimia yang dipakai untuk analisis sifat kimia selai jahe.

\section{Pelaksanaan Penelitian.}

Metode yang digunakan dalam penelitian ini adalah Rancangan Acak Kelompok (RAK) dengan dua faktor yaitu konsentrasi pektin kulit jeruk dan konsentrasi sukrosa dengan 6 kali percobaan dan 3 kali pengulangan.

Kulit jeruk ditimbang sebanyak $50 \mathrm{~g}$ kemudian dicuci dan dilakukan pemotongan. Selanjutnya kulit jeruk dihancurkan menggunakan blender dengan penambahan air sebanyak $100 \mathrm{ml}$. Panaskan sari kulit jeruk dengan suhu $100^{\circ} \mathrm{C} \pm 10$ menit kemudian disaring menggunakan saringan.

Proses pembuatan selai jahe adalah sebagai berikut : Jahe dikupas kulitnya, ditimbang sebanyak 500 g kemudian dicuci dan dilakukan pengecilan ukuran. Selanjutnya jahe dihancurkan menggunakan blender dengan penambahan air sebanyak $1000 \mathrm{ml}$ sehingga diperoleh larutan jahe. Larutan jahe yang diperoleh selanjutnya disaring dengan menggunakan saringan untuk memisahkan filtrate (sari) dan serat. $\mathrm{Ke}$ dalam filtrat ditambah asam sitrat 
sebanyak $1 \%$ dan dilakukan penambahan pektin sebanyak konsentrasi $0,5 \%$ (P1) dan $1 \% \quad(\mathrm{P} 2) \quad \mathrm{b} / \mathrm{v}$. Selanjutnya dilakukan pemasakan filtrat selama 3 sampai 5 menit pada suhu $60--65^{\circ} \mathrm{C}$ untuk melarutkan pektin dan asam sitrat. Tahap selanjutnya dilakukan penambahan sukrosa dengan konsentrasi $40 \% \quad(\mathrm{~S} 1), \quad 50 \% \quad(\mathrm{~S} 2)$, dan $60 \%$ (S3) b/v, kemudian dipanaskan selama 20 sampai 25 menit pada suhu $100^{\circ} \mathrm{C}$, dan dilakukan pengadukan terus menerus agar selai yang dihasilkan tidak mengkristal. Selanjutnya dilakukan pengujian spoon test untuk menentukan kekentalan selai yang ditandai dengan terpisahnya dua bagian selai ketika sendok diangkat, kemudian dilakukan pendinginan kemudian dikemas dengan menggunakan cup selai.

\section{Pengamatan}

Pengamatan yang dilakukan meliputi uji fisikokimia dan organoleptik. Analisa fisikokimia meliputi kadar air, $\mathrm{pH}$, gula reduksi dan warna. Sedangkan sifat organoleptik meliputi warna, rasa, tekstur (kekentalan) dan aroma terhadap kesukaan (hedonic) skor menggunakan 20 orang panelis dari kategori tidak terlatih.

\section{Analisa Data}

Analisa data fisikokimia dilakukan secara ANOVA menggunakan sofware Minitab 17 dengan selang kepercayaan 5\%. Apabila ditemukan pengaruh nyata terhadap salah satu variebel maka dilanjutkan dengan uji Tukey Untuk uji uji organoleptik menggunakan uji Friedman dan penentuan perlakuan terbaik fisikokimia dan organoleptik menggunakan metode Indeks Efektifitas.

\section{HASIL DAN PEMBAHASAN}

\section{Kadar Air}

Kadar air merupakan salah satu karakteristik yang sangat penting pada bahan pangan, karena air dapat mempengaruhi penampakan, tekstur, dan citarasa pada bahan pangan. Berdasarkan Tabel 1, rerata kadar air selai berkisar $12,2 \%$ sampai dengan 32,82\%. Hasil analisis sidik ragam menunjukkan bahwa penambahan pektin dan sukrosa memberikan pengaruh nyata terhadap kadar air selai jahe. Penambahan pektin $0,5 \%$ dan sukrosa $40 \%$ menghasilkan kadar air paling tinggi yaitu $32,82 \%$ sedangkan penambahan pektin $1 \%$ dan sukrosa $60 \%$ menghasilkan kadar air paling rendah yaitu $12,2 \%$. Semakin meningkatnya penambahan pektin dan sukrosa berkaitan dengan proses pembentukan gel, pada kondisi yang sesuai pektin akan menggumpal dan membentuk serabut halus yang mampu memerangkap air sehingga jumlah air bebas berkurang dan menyebabkan kadar air selai jahe menurun. Sukrosa berperan dalam proses dehidrasi yang membuat ikatan hidrogen pada pektin menjadi lebih kuat dan membentuk suatu jaringan polisakarida yang kompleks, sehingga menyebabkan air terperangkap di dalam jaringan (Shin et al., 2002).

Tabel 1. Rerata kadar air selai jahe.

\begin{tabular}{lll}
\hline Perlakuan & Rerata (\%) & Notasi \\
\hline P1S1 (pektin 0,5\% \& sukrosa 40\%) & $32,823 \pm 0,148$ & $\mathrm{a}$ \\
P1S2 (pektin 0,5\% \& sukrosa 50\%) & $25,196 \pm 0,134$ & $\mathrm{~b}$ \\
P1S3 (pektin 0,5\% \& sukrosa 60\%) & $25,186 \pm 0,148$ & $\mathrm{~b}$ \\
P2S1 (pektin 1\% \& sukrosa 40\%) & $14,223 \pm 0,125$ & $\mathrm{c}$ \\
P2S2 (pektin 1\% \& sukrosa 50\%) & $13,606 \pm 0,185$ & $\mathrm{~d}$ \\
P2S3 (pektin 1\% \& sukrosa 60\%) & $12,203 \pm 0,127$ & $\mathrm{e}$ \\
\hline
\end{tabular}

Ket: Notasi yang berbeda dalam setiap perlakukan menunjukan berbeda nyata pada uji Tukey. 
pH.

Tabel 2. Rerata $\mathrm{pH}$ selai jahe

\begin{tabular}{lll}
\hline Perlakuan & Rerata & Notasi \\
\hline P1S1 (pektin 0,5\% \& sukrosa 40\%) & $6,690 \pm 0,125$ & $\mathrm{a}$ \\
P1S2 (pektin 0,5\% \& sukrosa 50\%) & $6,216 \pm 0,119$ & $\mathrm{~b}$ \\
P1S3 (pektin 0,5\% \& sukrosa 60\%) & $5,246 \pm 0,138$ & $\mathrm{c}$ \\
P2S1 (pektin 1\% \& sukrosa 40\%) & $4,783 \pm 0,147$ & $\mathrm{~d}$ \\
P2S2 (pektin 1\% \& sukrosa 50\%) & $4,443 \pm 0,106$ & $\mathrm{e}$ \\
P2S3 (pektin 1\% \& sukrosa 60\%) & $4,213 \pm 0,164$ & $\mathrm{e}$ \\
\hline
\end{tabular}

Ket : Notasi yang berbeda dalam setiap perlakuan menunjukan berbeda nyata pada uji Tukey.

Tingkat keasaman atau $\mathrm{pH}$ berkaitan dengan konsentrasi ion hidrogen yang terkandung pada suatu larutan atau produk yang diukur. $\mathrm{pH}$ menunjukkan tingkat keasaman semakin rendah nilai $\mathrm{pH}$ semakin tinggi tingkat keasaman (Syahrumsyah et al., 2010).

Berdasarkan Tabel 2 rerata $\mathrm{pH} \quad 4,21$ sampai dengan 6,69. Hasil analisis sidik ragam menunjukkan bahwa penambahan pektin dan sukrosa memberikan pengaruh yang sangat nyata terhadap $\mathrm{pH}$ selai jahe. Penambahan pektin $1 \%$ dan sukrosa $60 \%$ menghasilkan $\mathrm{pH}$ paling tinggi yaitu 6,69 dan sedangkan penambahan pektin $1 \%$ dan sukrosa $40 \%$ menghasilkan $\mathrm{pH}$ paling rendah yaitu 4,21. Terjadinya kenaikan $\mathrm{pH}$ dengan semakin meningkatnya kadar sukrosa yang ditambahkan pada selai jahe berkaitan dengan proses pembentukan gel. Semakin tinggi nilai $\mathrm{pH}$, ketegaran gel yang terbentuk semakin meningkat. Nilai $\mathrm{pH}$ yang terlalu rendah menyebabkan gel semakin keras, sedangkan $\mathrm{pH}$ yang terlalu tinggi akan menyebabkan gel pecah (Sari, 2004).

\section{Gula Reduksi.}

Gula mempunyai sifat yang dapat menyebabkan reaksi pencoklatan yaitu karamelisasi (Yunita, 2013). Berdasarkan Tabel 3 rerata gula reduksi $0,21 \%$ sampai dengan $3,23 \%$. Penambahan pektin $0,5 \%$ dan sukrosa $40 \%$ menghasilkan gula reduksi paling tinggi yaitu $3,23 \%$ dan sedangkan penambahan pektin $1 \%$ dan sukrosa $60 \%$ menghasilkan gula reduksi paling rendah yaitu $0,21 \%$. Uji beda menunjukkan perlakuan P1S1 (pektin 0,5\% \& sukrosa $40 \%$ ) dan P1S2 (pektin 0,5\% \& sukrosa $50 \%$ ) tidak memiliki perbedaan yang nyata pada kadar gula reduksi. Penambahan sukrosa $60 \%$ memiliki perbedaan yang nyata dan penurunan kadar gula reduksi selai jahe. Hal ini disebabkan karena sukrosa merupakan gula non peruduksi dan tidak memiliki gugus karbonil bebas Menurut Estiasih, dkk (2016) sukrosa terdiri dari unit $\alpha$-D gluokopiranosil yang berikatan dengan ujung $\beta$-d fruktofuronasil, dimana ujung pereduksi berikatan dengan ujung pereduksi sehingga bersifat sebagai gula non pereduksi dan tidak memiliki gugus karbonil bebas (aldehid). Sukrosa Apabila gula ditambahkan ke dalam bahan pangan dalam konsentrasi yang tinggi (paling sedikit $40 \%$ padatan terlarut) sebagian air yang ada menjadi tidak tersedia untuk pertumbuhan mikroorganisme dan aktivitas air (aw) dari bahan pangan berkurang. 
Tabel 3. Rerata gula reduksi selai jahe.

\begin{tabular}{lll}
\hline \multicolumn{1}{c}{ Perlakuan } & Rerata & Notasi \\
\hline P1S1 (pektin 0,5\% \& sukrosa 40\%) & $3,23 \pm 0,1323$ & $\mathrm{a}$ \\
P1S2 (pektin 0,5\% \& sukrosa 50\%) & $3,03 \pm 0,1193$ & $\mathrm{a}$ \\
P1S3 (pektin 0,5\% \& sukrosa 60\%) & $2,75 \pm 0,1387$ & $\mathrm{~b}$ \\
P2S1 (pektin 1\% \& sukrosa 40\%) & $1,16 \pm 0,1474$ & $\mathrm{c}$ \\
P2S2 (pektin 1\% \& sukrosa 50\%) & $1,09 \pm 0,1060$ & $\mathrm{c}$ \\
P2S3 (pektin 1\% \& sukrosa 60\%) & $0,21 \pm 0,1646$ & $\mathrm{~d}$ \\
\hline
\end{tabular}

Ket : Notasi yang berbeda dalam setiap perlakuan menunjukan berbeda nyata pada uji Tukey.

Tabel 4. Rerata warna L selai jahe.

\begin{tabular}{llll}
\hline \multicolumn{1}{c}{ Perlakuan } & \multicolumn{1}{c}{$\mathrm{L}$} & \multicolumn{1}{c}{$\mathrm{a}$} & \multicolumn{1}{c}{$\mathrm{b}$} \\
\hline P1S1 (pektin 0,5\% \& sukrosa 40\%) & $38,03 \pm 0,111^{\mathrm{a}}$ & $14,96 \pm 0,161^{\mathrm{a}}$ & $18,97 \pm 0,115^{\mathrm{a}}$ \\
P1S2 (pektin 0,5\% \& sukrosa 50\%) & $36,14 \pm 0,129^{\mathrm{b}}$ & $14,96 \pm 0,126^{\mathrm{a}}$ & $17,74 \pm 0,121^{\mathrm{b}}$ \\
P1S3 (pektin 0,5\% \& sukrosa 60\%) & $35,45 \pm 0,166^{\mathrm{c}}$ & $14,68 \pm 0,152^{\mathrm{a}}$ & $15,71 \pm 0,157^{\mathrm{c}}$ \\
P2S1 (pektin 1\% \& sukrosa 40\%) & $31,99 \pm 0,108^{\mathrm{d}}$ & $13,20 \pm 0,1419^{\mathrm{b}}$ & $14,99 \pm 0,1637^{\mathrm{d}}$ \\
P2S2 (pektin 1\% \& sukrosa 50\%) & $24,03 \pm 0,133^{\mathrm{e}}$ & $12,18 \pm 0,156^{\mathrm{c}}$ & $12,06 \pm 0,144^{\mathrm{e}}$ \\
P2S3 (pektin 1\% \& sukrosa 60\%) & $22,72 \pm 0,146^{\mathrm{f}}$ & $8,73 \pm 0,152^{\mathrm{d}}$ & $9,04 \pm 0,150^{\mathrm{f}}$ \\
\hline
\end{tabular}

Ket : Notasi yang berbeda dalam setiap perlakuan menunjukan berbeda nyata pada uji Tukey.

\section{Warna}

Warna dinyatakan dalam 3 dimensi warna berdasarkan skala L, a dan b. Skala L dari 100 (cerah) sampai 0 (tidak cerah). Nilai a* menunjukkan + merah dan (-) hijau, sedangkan $b^{*}$ menunjukkan $(+)$ kuning sampai biru (-) Estiasih dkk, (2016). Berdasarkan Tabel 4, hasil analisis sidik ragam menunjukkan bahwa penambahan pektin dan sukrosa memberikan pengaruh yang sangat nyata terhadap warna selai jahe. Penambahan pektin $0,5 \%$ dan sukrosa $40 \%$ menghasilkan warna paling cerah yaitu 38,03 dan sedangkan penambahan pektin $1 \%$ dan sukrosa $40 \%$ menghasilkan warna tidak cerah yaitu 27,72. Warna selai kecerahan (L*) berkisar 22,72 - 38,03, kemerahan $\left(\mathrm{a}^{*}\right)$ berkisar 8,73 - 14,96 dan kekuningan $\left(b^{*}\right)$ berkisar $9,05 \%-18,97 \%$. Secara keseluruhan nilai warna $(\mathrm{L} * \mathrm{a} * \mathrm{~b} *)$ menunjukkan bahwa kecerahan $\left(\mathrm{L}^{*}\right)$, kemerahan $\left(a^{*}\right)$ dan kekuningan $\left(b^{*}\right)$ cenderung mengalami peningkatan seiring dengan meningkatnya proporsi pektin dan sukrosa. Menurut Javanmard dan Endan (2010), perubahan warna disebabkan karena beberapa faktor seperti suhu, $\mathrm{pH}$, dan oksigen. Perubahan warna terjadi karena adanya polimerisasi pada saat pemanasan yang disebakan adanya degradasi sukrosa.

\section{Organoleptik}

Rasa melibatkan panca indera yaitu lidah, agar suatu senyawa dapat dikenali rasanya, senyawa tersebut harus dapat mengadakan hubungan dengan mikrovilus dan impuls yang terbentuk dan dikirim melalui syaraf ke pusat susunan syaraf. 


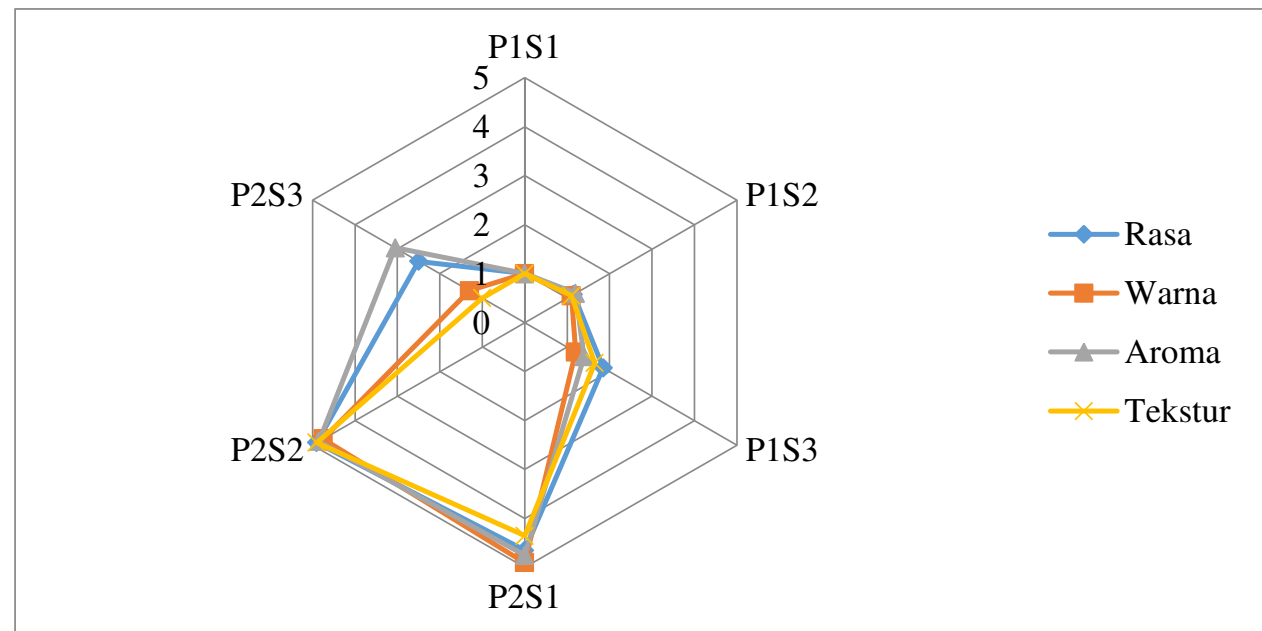

Keterangan :P1S1 (pektin 0,5\% dan sukrosa 40\%), P1S2 (pektin 0,5\% dan sukrosa $50 \%$ ), P1S3 (pektin 0,5\% dan sukrosa 60\%), P2S1 (pektin 1\% dan sukrosa 40\%), P2S2 (pektin 1\% dan sukrosa 50\%), P2S3 (pektin 1\% dan sukrosa $60 \%$ ).

Gambar 1. Grafik rata-rata organoleptik kesukaan rasa selai jahe

Nilai kesukaan panelis pada uji organoleptik rasa selai jahe menunjukan nilai tertinggi terdapat pada perlakuan P2S2 (pektin 1\% dan sukrosa 50\%) dengan ratarata nilai 4,90 (sangat suka). Dari data tersebut penambahan $50 \%$ sukrosa lebih diminati oleh panelis daripada sukrosa $40 \%$ dan $60 \%$. Perbandingan antara selai yang ditambah pektin kulit jeruk $0.5 \%$ dengan pektin kulit jeruk $1 \%$ menunjukkan bahwa penambahan pektin dan sukrosa berpengaruh nyata terhadap nilai kesukaan panelis pada selai jahe. Semakin tinggi penambahan pektin dan sukrosa maka rasa selai yang dihasilkan semakin manis. Rasa selai jahe dipengaruhi oleh sukrosa, asam sitrat, dan pektin yang ditambahkan dalam pembuatan selai. Sukrosa, asam, glukosa, dan fruktosa dapat mempengaruhi rasa produk pangan sehingga meningkatkan tingkat kesukaan pada produk tersebut.

Warna pada suatu makanan sangatlah penting, karena dapat membangkitkan selera makan. Warna makanan yang menarik dapat memengaruhi dan membangkitkan selera makan konsumen, bahkan warna dapat menjadi petunjuk bagi kualitas makanan yang dihasilkan. Warna juga mempunyai peran dan arti yang sangat penting pada komoditas pangan karena memengaruhi penerimaan konsumen terhadap komoditas tersebut (Winarno, 2004).

Nilai kesukaan panelis pada uji organoleptik warna selai jahe menunjukan nilai tertinggi terdapat pada perlakuan P2S1 (pektin 1\% dan sukrosa 40\%) dengan ratarata nilai 4,90 (sangat suka). Dari data tersebut penambahan $40 \%$ sukrosa lebih diminati oleh panelis daripada sukrosa $50 \%$ dan $60 \%$. Perbandingan antara selai yang ditambah pektin kulit jeruk $0.5 \%$ dengan pektin kulit jeruk $1 \%$ menunjukkan bahwa penambahan pektin dan sukrosa berpengaruh nyata terhadap nilai kesukaan panelis pada selai jahe.

Aroma adalah bau yang sukar diukur sehingga biasanya menimbulkan pendapat yang berlainan dalam menilai kualitas aromanya. Perbedaan pendapat disebabkan setiap orang memiliki perbedaan penciuman, meskipun mereka dapat membedakan aroma namun setiap orang mempunyai kesukaan yang berlainan (Kartika, et al., 1988).

Nilai kesukaan panelis pada uji organoleptik aroma selai jahe menunjukan nilai tertinggi pada perlakuan P2S2 (pektin $1 \%$ dan sukrosa 50\%). Penilaian tertinggi terdapat pada perlakuan P2S2 (pektin 1\% dan sukrosa 50\%) dengan rata-rata nilai 4,85 
(sangat suka). Dari data tersebut penambahan $50 \%$ sukrosa lebih diminati oleh panelis daripada sukrosa $40 \%$ dan $60 \%$. Perbandingan antara selai yang ditambah pektin kulit jeruk $0.5 \%$ dengan pektin kulit jeruk $1 \%$ menunjukkan bahwa penambahan pektin dan sukrosa berpengaruh nyata terhadap nilai kesukaan panelis pada selai jahe. Menurut Setyaningsih, et al. dalam Nofalina (2013) penilaian terhadap tekstur produk dapat dilakukan perabaan dengan ujung jari tangan. Tekstur bersifat kompleks dan terkait dengan struktur bahan yang terdiri dari tiga elemen yaitu mekanik (kekerasan, kekenyalan), geometric (berpasir, beremah) dan mouthfeel (berminyak, berair).

Nilai kesukaan panelis pada uji organoleptik tekstur (kekentalan) selai jahe menunjukan nilai tertinggi terdapat pada perlakuan P2S2 (pektin 1\% dan sukrosa $50 \%$ ) dengan rata-rata nilai 4,90 (sangat suka). Dari data tersebut penambahan $50 \%$ sukrosa lebih diminati oleh panelis daripada sukrosa $40 \%$ dan $60 \%$. Perbandingan antara selai yang ditambah pektin kulit jeruk $0.5 \%$ dengan pektin kulit jeruk 1\% menunjukkan bahwa penambahan pektin dan sukrosa berpengaruh nyata terhadap nilai kesukaan panelis pada selai jahe.

\section{Pemilihan Perlakuan Terbaik Dengan Metode Indeks Efektifitas}

Penentuan perlakuan terbaik pada selai jahe dilakukan dengan menggunakan metode indeks efektifitas. Metode ini dilakukan pada parameter kimiawi meliputi uji kadar air, pH, gula reduksi dan warna serta uji fisik yang meliputi warna, rasa, aroma dan tekstur (kekentalan).

Hasil perhitungan menunjukkan perlakuan terbaik terdapat pada perlakuan P2S2 (Pektin 1\% dan Sukrosa 50\%) dengan ketentuan fisiko kimia kadar air 32,86\%, $\mathrm{pH}$ 6,59\%, Gula reduksi 3,08\%, warna L 38,20, serta organoleptik dengan ketentuan rasa 4,90 (sangat suka), warna 4,90 (sangat suka), tekstur 4,90 (sangat suka), dan aroma 4,85 (sangat suka).

\section{KESIMPULAN DAN SARAN}

\section{Kesimpulan}

Berdasarkan hasil penelitian dapat disimpulkan bahwa :

1. Perlakuan penambahan pektin kulit jeruk berpengaruh nyata terhadap kadar air, $\mathrm{pH}$, gula reduksi, warna fisik dan penilaian sensori selai.

2. Perlakuan penambahan sukrosa berpengaruh nyata terhadap kadar air, $\mathrm{pH}$ gula reduksi, warna fisik dan penilaian sensori selai.

3. Hasil perhitungan menunjukkan perlakuan terbaik terdapat pada perlakuan P2S2 (Pektin 1\% dan Sukrosa 50\%) dengan ketentuan fisiko kimia kadar air $32,86 \%$, pH 6,59, Gula reduksi 3,08\%, warna L 38,20, serta organoleptik dengan rasa 4,90 (sangat suka), warna 4,90 (sangat suka), tekstur 4,90 (sangat suka), dan aroma 4,85 (sangat suka)

Tabel 5. Indeks Efektifitas Fisikokimia dan Organoleptik

\begin{tabular}{ll}
\hline \multicolumn{1}{c}{ Perlakuan } & \multicolumn{1}{c}{ Rata-rata } \\
\hline P1S1 (pektin 0,5\% \& sukrosa 40\%) & 0.2571 \\
P1S2 (pektin 0,5\% \& sukrosa 50\%) & 0.203 \\
P1S3 (pektin 0,5\% \& sukrosa 60\%) & 0.227 \\
P2S1 (pektin 1\% \& sukrosa 40\%) & $0.335^{* 2}$ \\
P2S2 (pektin 1\% \& sukrosa 50\%) & $0.360^{* 1}$ \\
P2S3 (pektin 1\% \& sukrosa 60\% & $0.198^{* 3}$ \\
\hline
\end{tabular}

Keterangan : ${ }^{* 1}$ : terbaik $1,{ }^{* 2}$ : terbaik $2,{ }^{* 3}$ : terbaik 3 


\section{Saran}

1. Perlu dilakukan penelitian lebih lanjut mengenai kajian umur simpan produk selai jahe.

2. Perlu dilakukan Penelitian selai jahe dalam bentuk lembaran.

\section{DAFTAR PUSTAKA}

De Garmo, E. P., Sullivan, W. G ., dan Canada, C. R. (1984). Engineering Economy. Seventh Edition. New York: Mc Millan Publ. Co.

Estiasih, T., Harijono, Waziroh, E., dan Fibrianto, K. (2016). Kimia dan Fisik Pangan. Bumi Aksara.

Fachruddin, L. (1997). Membuat Aneka Selai. Yogyakarta : Kanisius.

Javanmard, M dan J. Endan. (2010). A survey on rheological properties of fruit jams. Journal of Chemical Engineering and Applications 1(1):17.

Kartika, B., Pudji, H., dan Wahyu, S. (1988). Pedoman Uji Inderawi Bahan Pangan. Pusat Antar Universitas Pangan dan Gizi, Yogyakarta.

Ramadhan, A.J. (2013). Aneka Manfaat Ampuh Rimpang Jahe untuk Pengobatan. Diandra Pustaka Indonesia. Yogyakarta.

Sari, M. L. (2004). Pengaruh Penambahan Sukrosa dan Pektin Terhadap Sifat Kimia dan Organoleptik Selai Stroberi. (Skripsi). Jurusan Teknologi Hasil Pertanian. Universitas Lampung. Bandar Lampung. 55 hlm.

Shin, J.E., L. Salim dan P. Cornillon. (2002). The effect of centrifugation on agar/sucrose gels. Journal of Food Hydrocolloids 16(2) :89-94.
Winarno F.G. (2004). Kimia Pangan dan Gizi. PT Gramedia Pustaka Utama. Jakarta.

Yunita, S. (2013). Pengaruh Jumlah Pektin Dan Gula Terhadap Sifat Organoleptik Jam Buah Naga Merah (Hylocereus Polyrhizus). Universitas Negeri Surabaya. 